\title{
Cap-assisted retrograde single-balloon enteroscopy results in high terminal ileal intubation rate
}

Authors

Institution
Darin L. Dufault, Andrew S. Brock

Division of Gastroenterology and Hepatology, Department of Medicine, Medical University of South Carolina, South Carolina United States submitted:

13. July 2015

accepted after revision:

5. November 2015

\section{Bibliography}

DOI http://dx.doi.org/

10.1055/s-0041-109541

Published online: 11.1.2016

Endoscopy International Open

2016; 04: E202-E204

(c) Georg Thieme Verlag KG

Stuttgart · New York

E-ISSN 2196-9736

Corresponding author:

\section{Darin L. Dufault MD}

Division of Gastroenterology \& Hepatology

Medical University of South

Carolina

114 Doughty St., Suite 249

MSC 702

Charleston, SC 29425-2900

Phone: +1-843-792-2301

Fax: $+1-843-876-7232$

dufaultd@musc.edu
Background and study aims: Retrograde singleballoon enteroscopy (RSBE) facilitates evaluation of the distal small bowel and provision of appropriate therapy when necessary. Intubation of the terminal ileum (TI) is a major rate-limiting step, with failure rates as high as $30 \%$. Cap-assisted endoscopy has proven beneficial in other aspects of endoscopy. We have noticed that it similarly aids in TI intubation during RSBE by facilitating opening of the ileocecal valve (ICV). The primary aim of this study was to measure the TI intubation rate using cap-assisted RSBE. Other procedural details and outcomes were also measured.

Patients and methods: A total of 36 consecutive RSBEs performed between July 2011 and May 2014 at the Medical University of South Carolina were retrospectively reviewed. All procedures were performed or supervised by our center's

\section{Introduction}

Retrograde single-balloon enteroscopy (RSBE) is an established modality for diagnosis and treatment of distal small bowel lesions that are beyond the reach of standard ileocolonoscopy. However, it is a challenging and complicated procedure requiring significant time and skill beyond standard endoscopy. A major barrier to retrograde enteroscopy is intubation of the terminal ileum (TI), with failure rates documented as high as $30 \%$ [1]. This is due to the lack of stiffness in the relatively small-caliber enteroscope, which often results in looping of the instrument when trying to intubate the TI. Cap-assisted endoscopy has previously proven beneficial for several aspects of endoscopy, including cecal intubation, adenoma detection, and visualization of the ampulla of Vater by peeling away mucosal folds [2-4]. Similarly, we have found that a distal cap aids in many aspects of retrograde balloon enteroscopy, including intubation of the TI, by facilitating opening of the ileocecal valve (ICV). Therefore, we set out to deter- small bowel endoscopist (ASB). Outcomes measured included $\mathrm{TI}$ intubation rate, procedure time, depth of maximal insertion (DMI), diagnostic yield (DY), therapeutic yield (TY), and complications.

Results: The TI intubation rate was $97 \%$ (35/36). The one failure was due to stool completely obscuring the cecum. Median procedure time was 54 minutes, with a mean DMI of $68 \mathrm{~cm}$ beyond the ICV. The technical success rate was $86 \%$, whereas DY and TY were $61 \%$ and $25 \%$, respectively. There were no complications. The study was limited in that it involved a single endoscopist at a single center.

Conclusions: Cap-assisted RSBE results in a high TI intubation rate, without compromise to safety or procedural yield.

mine the terminal ileal intubation rate during RSBE while utilizing a distal cap, as well as procedural outcome variables.

\section{Patients and methods \\ $\nabla$}

We reviewed all RSBEs performed at our institution between July 2011 and May 2014.All RSBEs were performed or supervised by our center's adult small bowel endoscopist (ASB) under general or monitored anesthesia care (MAC) with the exception of one performed with moderate sedation. All procedures were performed with an enteroscope (SIF-Q180; Olympus USA, Center Valley, Pennsylvania, USA) with the single-balloon overtube. All procedures utilized a distal cap. Patient demographics, procedural indication, procedure time, depth of insertion beyond the ICV, exam findings, treatments performed, and complications were reviewed. We then calculated TI intubation rate, median procedure time, mean depth of maximal insertion beyond the ICV, technical 
success, diagnostic yield, therapeutic yield, and complication rate. The TI intubation rate was defined as the proportion of procedures in which we were able to intubate the TI at least $5 \mathrm{~cm}$. Technical success was defined as previously by the proportion of procedures in which we were able to evaluate at least $20 \mathrm{~cm}$ beyond the ICV [5]. Diagnostic yield was defined as previously by the proportion of technically successful procedures in which a diagnosis was determined. Therapeutic yield was defined as previously by the proportion of technically successful procedures in which a therapy was applied. This study was approved by the Medical University of South Carolina's Institutional Review Board for Human Research.

\section{Results \\ $\nabla$}

A total of 36 RSBEs were reviewed. The mean age was 59 ( $50 \%$ female). Indications included bleeding, anemia, mass or polyp seen on capsule endoscopy or imaging, ulcers seen on capsule endoscopy, stricture, and other. Demographics and indications are shown in 0 Table1. TI intubation was successful in 35 of 36 procedures (97\%). Median procedure time was 54 minutes, and the mean depth of maximal insertion was $68 \mathrm{~cm}$ beyond the ICV. Technical success was achieved in 31 of 36 procedures (86\%). A diagnosis was identified in 22 of 36 cases, giving a diagnostic yield of $61 \%$. Therapy was provided in 9 of 36 cases, giving a therapeutic yield of $25 \%$. Table 2 demonstrates all diagnoses and applicable therapies. There were no complications.

\section{Discussion \\ $\nabla$}

RSBE has proven to be an effective method for evaluating the distal small bowel. One limiting step in the ability to perform RSBE is intubation of the TI. To our knowledge, this is the first study to demonstrate the utility of a distal cap in RSBE. Our results suggest that use of a distal attachment seems to aid in the success of RSBE by facilitating TI intubation. The single failure we experienced was due to stool completely obscuring the cecum. In addition, the technical success rate was $86 \%$, due to two failures noted to have poor prep, including the aforementioned complete obstruction of the cecum with stool, and three noted to have looping due to floppy colons. The diagnostic yield was $61 \%$, with findings typical of RSBE, including primarily arteriovenous malformations, as also polyps, nodules, and ulcers. Although many biopsies were performed, they are not considered therapy. As such, therapeutic yield was calculated to be $25 \%$, consisting only of argon plasma coagulation (APC) for hemostasis of bleeding lesions, and polypectomy.

One limitation of this case series is that it reflects the experience of a single endoscopist at a single center. Further, we had no comparison group as very few RSBEs have been performed without a distal attachment at our institution. However, our procedure time, depth of maximal insertion, diagnostic and therapeutic yields, and rates of technical success and complications are comparable to published values [6-8].

We believe that this case series shows that the use of a distal cap is likely to aid in the success of RSBE by facilitating intubation of the TI. Although RSBE will certainly remain challenging, the attachment of a distal cap is one tool that other small-bowel endoscopists may find beneficial, without obvious compromise to efficacy or safety.
Table 1 Demographics and Indications.

\begin{tabular}{|ll|}
\hline Demographics & $\mathbf{n}(\%)$ \\
\hline Mean Age & $59($ range 15-88) \\
\hline Females & $18(50)$ \\
\hline Indication & \\
\hline Bleeding/anemia & $21(58)$ \\
\hline Mass or polyp & $7(19)$ \\
\hline Ulcers on capsule & $3(8)$ \\
\hline Stricture & $2(6)$ \\
\hline Other & $3(8)$ \\
\hline
\end{tabular}

Table 2 Findings and therapies

\begin{tabular}{|c|c|}
\hline Findings & Therapy \\
\hline \multicolumn{2}{|l|}{ Nodular lymphoid hyperplasia $75 \mathrm{~cm}$ proximal to ICV } \\
\hline Angioectasia $30 \mathrm{~cm}$ proximal to the ICV & APC \\
\hline \multicolumn{2}{|l|}{ Diverticulosis } \\
\hline \multicolumn{2}{|l|}{ Distal ileal ulcerated strictures } \\
\hline $\begin{array}{l}\text { Diminutive ileal angioectasia, } 2 \text { ascending colon } \\
\text { angioectasia }\end{array}$ & APC \\
\hline $\begin{array}{l}\text { Oozing colonic angioectasia; non-bleeding mid-ileum } \\
\text { angioectasia }\end{array}$ & APC \\
\hline \multicolumn{2}{|l|}{ Two nodules in distal ileum } \\
\hline \multicolumn{2}{|l|}{ Moderately severe stenosis in the distal ileum } \\
\hline \multicolumn{2}{|l|}{ Moderately severe stenosis in the terminal ileum } \\
\hline Colon angioectasia & APC \\
\hline \multicolumn{2}{|l|}{ Moderately erythematous mucosa in the ileum } \\
\hline Angioectasia in distal and mid-ileum & APC \\
\hline Angioectasia in ileum & APC \\
\hline \multicolumn{2}{|l|}{ Erythema and erosions near $\mathrm{AO}$} \\
\hline Ileal angioectasia & APC \\
\hline \multicolumn{2}{|l|}{ Normal ileum, moderate diverticulosis } \\
\hline \multicolumn{2}{|l|}{ Submucosal nodule in the distal ileum (lipoma) } \\
\hline \multicolumn{2}{|l|}{ Aphthous ulcers in the mid-ileum and terminal ileum } \\
\hline \multicolumn{2}{|l|}{ Meckel's diverticula $65 \mathrm{~cm}$ proximal to the ICV } \\
\hline \multicolumn{2}{|l|}{ Benign Ulcer $80 \mathrm{~cm}$ proximal to the ICV } \\
\hline Polyp in the distal ileum & Polypectomy \\
\hline $\begin{array}{l}12-\mathrm{mm} \text { ulcerated pedunculated fibroid polyp } 50 \mathrm{~cm} \\
\text { proximal to the ICV }\end{array}$ & Polypectomy \\
\hline
\end{tabular}

ICV, ileocecal valve; APC, argon plasma coagulation; AO, appendiceal orifice

Competing interests: None 


\section{References}

1 Mehdizadeh S, Ross A, Gerson L et al. What is the learning curve associated with double balloon enteroscopy? Technical details and early experience in 6 US tertiary care centers Gastrointest Endosc 2006; 64: $740-750$

2 Dik VK, Moons LM, Siersema PD. Endoscopic innovations to increase the adenoma detection rate during colonoscopy. World J Gastroenterol 2014; 7: 2200-2211

3 Frieling T, Neuhaus F, Kuhlbusch-Zicklam $R$ et al. Prospective and randomized study to evaluate the clinical impact of cap assisted colonoscopy (CAC). Z Gastroenterol 2013; 51: 1383-1388

4 Choi YR, Han JH, Cho YS et al. Efficacy of cap-assisted endoscopy for routine examining the ampulla of Vater. World J Gastroenterol 2013; 19: $2037-2043$
5 Upchurch BR, Sanaka MR, Lopez AR et al. The clinical utility of singleballoon enteroscopy: a single-center experience of 172 procedures. Gastrointest Endosc 2010; 71: 1218-1223

6 Efthymiou M, Desmond P, Brown G et al. SINGLE-01: a randomized, controlled trial comparing the efficacy and depth of insertion of singleand double-balloon enteroscopy by using a novel method to determine insertion depth. Gastrointest Endosc 2012; 76: 972-980

7 Tsujikawa T, Saitoh Y, Andoh A et al. Novel single-balloon enteroscopy for diagnosis and treatment of the small intestine: preliminary experiences. Endoscopy 2008; 40: 11-15

8 Frantz DJ, Dellon ES, Grimm IS et al. Single-balloon enteroscopy: results from an initial experience at a U.S. tertiary-care center. Gastrointest Endosc 2010; 72: 422-426 